\title{
ES INÚTIL, NO OS ENGAÑ́́IS, SOMOS LO QUE SOMOS
}

\author{
Salvatore TARANTINO-CURSERI \\ Investigador independiente, Venezuela \\ sig.staran@yahoo.com
}

\section{IT IS USELESS, DON'T BE DECEIVED, WE ARE WHAT WE ARE}

Resumen: Es inútil, no os engañéis, somos lo que somos. Lejos de ser una sentencia pesimista es más bien, bastante realista, solo que no queremos aceptarlo. Bastaría con sincerarnos con nuestro «yo» y esto es precisamente el objetivo de este opúsculo. A través del marco teórico y la disertación, se pretende incentivar una hermenéutica reflexiva en torno a cuatro conceptos con una gran carga histórica, filosófica, lingüística, ideológica, semántica, etc., "Naturaleza Humana", "Persona", "Mentira" y la "Verdad". Conceptos que nos definen y explican por qué somos como somos. Se colocará el acento en la voz de origen griego $\lambda$ ó éste junto con el reemplazo del singular «yo» por su plural «nosotros», conforman la ecuación que nos permitirá evadir nuestra auto-extinción.

Abstract: It is useless, don't be deceived, we are what we are. Far from being a pessimistic statement it is rather quite realistic, just do not want to accept it. It would suffice to be sincere with our "I" and this is precisely the aim of this booklet. Through the theoretical framework and the dissertation is intended to encourage a reflective hermeneutics around four concepts with a great historical, philosophical, linguistic, ideological, semantic, etc., "Human Nature", "Person", "Lie" and the "Truth". Concepts that define and explain why we are like we are. the accent on the word of Greek origin $\lambda$ ó $\gamma \mathrm{os}$ «lôgos» as it will be placed along with the replacement of the singular "I" by its plural "we" make the equation that will allow us to evade our self-extinction.

Palabras clave: Naturaleza Humana, Persona, Mentira, Verdad, Sinceridad, Logos

Human Nature, Person, Lie, Truth, Sincerity, Logos 
"Todo es perfecto cuando sale de las manos de Dios, pero todo degenera en las manos del hombre. Obliga a una tierra a que dé lo que debe producir otra, a que un árbol dé un fruto distinto; mezcla y confunde los climas, los elementos y las estaciones, mutila su perro, su caballo y su esclavo; lo turba y desfigura todo; ama la deformidad, lo monstruoso; no quiere nada tal como ha salido de la naturaleza, ni al mismo hombre, a quien doma a su capricho, como a los árboles de su huerto" (Rousseau, Emilio o la educación).

\section{Marco Teórico}

Con la idea de construir un diálogo fértil y robustecer la disertación de lo planteado en el título, se consideró conveniente definir, muy someramente, los términos "Naturaleza Humana", "Persona", "Mentira", "Verdad" y colocar el acento en la voz de origen griego $\lambda o ́ \gamma o \varsigma$ «lôgos» ya que constituyen la piedra angular y centro de gravedad de este artículo.

\section{Naturaleza Humana}

Lastimosamente no sentimos la necesidad de vestirnos, con un paso hacia delante y dos hacia tras, por más que lo intentamos, seguimos siendo monos desnudos.

Con la gran carga histórica, filosófica, lingüística, ideológica, semántica, etc., etc., que circunscribe "Naturaleza Humana", tratar el tópico, no es tarea trivial y mucho menos sencilla, de hecho, el autor de este opúsculo pide disculpas por su osado atrevimiento de acotarlo y resumirlo a fin de mantenerse dentro de las fronteras del diálogo planteado.

El concepto de "Naturaleza Humana" envuelve una notable polisemia (de "poli", muchos, y el griego " $\sigma \eta ́ \eta \mu$ ", significado), su temática es tan extensa que abarca aseveraciones tan disímiles como "la no inexistencia de tal naturaleza" de Sartre y "la designación de ciencia primera de carácter filosófico" de Hume, como la "imagen idílica de la naturaleza humana" de Rousseau y la "naturaleza humana es esencialmente belicosa, egoísta y antisocial" de Hobbes.

El filósofo inglés Thomas Hobbes (1588-1679) maneja el concepto de "Naturaleza Humana" en una forma bastante peculiar e interesante para la época. Se ocupó de él desde cinco aristas: la antropológica, la epistemológica, la ética, la política y la teología. Quizás por el contexto histórico (el sistema de Copérnico, las teorías físicas y matemáticas de Galileo, el rigor metódico de la filosofía de Descartes, el descubrimiento de América, la guerra civil y la inestabilidad política que asolaba a Inglaterra (Europa padece la Guerra de los Treinta Años), etc.) que le tocó vivir, Hobbes, tratando de buscar las razones y el porqué de la guerra, llega a la conclusión, maquiaveliana, que la naturaleza humana es esencialmente belicosa, egoísta y antisocial.

Al respecto, el doctor y profesor / investigador titular, adscrito al Departamento de Relaciones Sociales de la Universidad Autónoma Metropolitana (México) y miembro del Sistema Nacional de Investigadores, Gerardo Ávalos Tenorio en su obra Leviatán y Behemoth. Figuras de la idea del Estado, nos comenta que (2001: 85):

“Así, tras las huellas de Maquiavelo, Thomas Hobbes diseñó su idea de Estado absoluto sobre la base de pretensiones de cientificidad en la descripción de la naturaleza humana: dado que el hombre busca el placer y se aleja del dolor $\mathrm{y}$, en consecuencia, entra en conflicto con los otros para obtener los bienes, 
la situación natural de los hombres es la guerra de todos contra todos. La manera de superar ese estado es mediante un pacto de asociación entre sí y de sumisión a un hombre o a una asamblea que, a partir de entonces, ejerce el poder soberano".

El doctor y profesor Emérito de la Universidad Nacional de Educación a Distancia (UNED), Joaquín Rodríguez Feo en su obra Thomas Hobbes - Tratado sobre el Ciudadano nos comenta (2009: 16, 47):

"Pero esta concepción aristotélica, armoniosa y progresiva, no daba cuenta debidamente de los fenómenos contradictorios y agresivos que preocupaban a Hobbes. Por eso prefiere el modelo iusnaturalista (Grocio acababa de publicar De iure belli ac pacis) en el que se parte de un estado de naturaleza, de características negativas para la vida humana, del que se ha de evolucionar hasta la constitución del Estado, donde queda garantizada la supervivencia y la prosperidad de los ciudadanos. De qué forma y en qué etapas haya de producirse ese proceso es lo que caracteriza la teoría política de Hobbes [...] Fijados pues dos postulados certísimos de la naturaleza humana: uno el de la natural codicia, por la cual todos quieren apropiarse del uso de las cosas comunes, y otro el de la razón natural por la que todos tratan de evitar la muerte violenta como el mal supremo de la naturaleza; de ahí me parece haber demostrado en esta obra con una deducción evidentísima la necesidad de respetar los pactos y la fe dada y, consecuentemente, los elementos de la virtud moral y de los deberes civiles".

Hobbes, con sus dos tratados de filosofía política, De Cive (1642) y Leviathan (1651) y sus dos máximas «Hommo homini lupus» y «Bellum omnium contra omnes», con Maquiavelo en el trasfondo, edificó uno de los grandes pilares de la teoría política de todos los tiempos, piedra angular y andamio de la ciencia política actual.

Por otro lado, encontramos al filósofo, economista, sociólogo e historiador escocés, David Hume (1711-1776), quien con su magistral tratamiento del tópico, logra estremecer las columnas epistemológicas de la época. Este conspicuo Homo Sapiens, estriba su planteamiento sobre el poder determinístico newtiano de las leyes de la naturaleza y plantea el necesario tratamiento científico al concepto de "Naturaleza Humana", de hecho, en su inmortal obra Tratado de la naturaleza humana coloca como subtítulo "Ensayo para introducir el método del razonamiento experimental en los asuntos morales" (Hume, 1988), en pocas palabras, Hume, con un claro rechazo a la suma de monólogos en el diálogo de sordos característico de la multi-disciplinariedad, plantea la necesaria simbiosis entre la filosofía y las ciencias en su innovador tratamiento inter y transdisciplinar al concepto de "Naturaleza Humana", donde asegura que dicho concepto trasciende, en forma categórica, a las demás esferas del saber.

$\mathrm{Al}$ respecto, la Dra. Ángela Calvo de Saavedra, en su obra El carácter de la "verdadera filosofía” de David Hume nos dice (2012: 33, 77):

"Hume es pionero en postular la ciencia de la naturaleza humana como ciencia primera de carácter filosófico -no empírico- cuya tarea es establecer los límites de todo conocimiento mediante el minucioso examen de la dinámica operatoria del entendimiento y de las pasiones. Ese es el sentido literal del proyecto de conquista de la capital: conquistar la naturaleza humana y erigir ese saber filosófico en origen de todo saber. [...] Al plantear en el Tratado que procederá mediante la "observación cuidadosa de la vida humana", Hume asume que la interacción social habitual es el escenario propio de la "verdadera filosofía". El 
enfoque de la obra es una "fenomenología de la mente" que se configura como naturaleza humana en la experiencia social; lo específicamente fenomenológico de esta empresa es reconocer el mundo de la vida como escenario, génesis y destino de toda teoría. [...] en la metáfora humeana no serán la metafísica ni la geometría los fundamentos de la filosofía moral ni de la filosofía natural, sino una nueva ciencia: la de la naturaleza humana".

Siguiendo por el sendero histórico de la "Naturaleza Humana", encontramos al polímata suizo francófono, Jean Jacques Rousseau (1712-1778), quien en claro contraste con Hobbes, éste, con una visión radicalmente anti-política y digno representante de la corriente angelista, manejó el sentimiento, como principal atributo del homo y abogó, con firmeza, por la figura idílica del hombre bueno.

Este insigne estudioso de la naturaleza humana, usó como estandarte de su planteamiento dos máximas «El hombre nace libre, pero vive encadenado» $\mathrm{y}$ «El hombre es bueno por naturaleza»

Rousseau en su obra El contrato social (1868), al inicio del capítulo I nos dice que el hombre nace libre, y sin embargo, se desarrolla y vive entre cadenas. Quien se considera amo, no deja por eso de ser menos esclavo que los demás y en el capítulo II, nos sigue diciendo que habiendo nacido todo hombre libre y dueño de sí mismo, nadie puede, bajo ningún pretexto, sujetarlo, sin su consentimiento. El decidir o declarar que todo hijo de un esclavo nace, de por sí, esclavo, es aseverar que no nace hombre.

En Emilio o la educación (1982), en el cuarto libro, nos dice que el hombre es naturalmente bueno; que lo sienta en sí y juzgue de su prójimo por sí mismo pero que vea cómo la sociedad deprava y pervierte a los hombres; encuentre en las preocupaciones de éstos la causa de todos sus vicios; tenga inclinación a estimar a cada individuo, pero desprecie la muchedumbre; vea que todos llevan casi una misma máscara, pero sepa que hay rostros más hermosos que la máscara que los encubre.

Desde otro ángulo, partiendo del sentido filosófico del término "naturaleza", abonado con una clara postura atea y con carácter determinante y eminentemente antropológico de la Filosofía Existencialista Atea, cuyo principal exponente fue el francés Jean Paul Sartre (1905-1980), quien con su máxima "la existencia precede su esencia", afirma la no existencia de Dios, por ende, difícilmente el humano pueda tener algo previo a su existencia que lo determine y lo defina, así pues, parafraseándolo, no podemos hablar de naturaleza humana, ya que no hay un Dios para concebirla. El hombre comienza con ser "nada" y a medida que se desarrolla, que interactúa con su entorno, es cuando se define quien es, es él quien definirá su ser y será tal como se haya proyectado ser, será tal como él se conciba, en definitiva, él, y solo él, será producto idílico de sí mismo.

Con su correspondiente desarrollo posterior en pro de un porvenir, su definición y razón de ser, solo tendrá sentido, después que acaezca el acto de existir y no antes. De esta forma, el posible concepto de "Naturaleza Humana" no tiene ningún sentido, de hecho, para los existencialistas ateos es tan solo un planteamiento apagógico (reductio ad absurdum).

El autor de este opúsculo, en clara sintonía, comulga con lo señalado por el doctor y profesor agregado de filosofía en la Universidad Católica de Lovaina (Bélgica), miembro de la Comisión Teológica Internacional desde 1987 a 1991 y Obispo de Namur desde 1991, Leonard André Mutien quien nos dice (2006: 822, 823, 824):

"La palabra «naturaleza» se refiere tanto al mundo físico y a las cosas que se producen en el universo sin intervención humana alguna, como a la esencia de algo, al estado primitivo y sin cultivar de un ser vivo o de un lugar. La mayoría de los malentendidos relativos al concepto de «naturaleza humana» y al empleo de «ley natural» en moral se deben a la rica ambigüedad del término 
«naturaleza». [...] «Naturaleza» viene del sustantivo latino natura, que se construye a partir del participio pasado natus del verbo nasci, y que significa «nacer». Etimológicamente, el término «naturaleza» designa la situación en la que viene a la vida un ser, y el estado que hereda. Basándonos en este significado etimológico, naturaleza se contrapone a cultura, ya que el término «cultura» viene del latín tolere, que significa «cultivar». Si la naturaleza de una cosa se reduce a su estado de nacimiento, entonces la cultura se opone a naturaleza. [...] La ambigüedad del término «naturaleza» puede extenderse a otros ámbitos colindantes. Entre las acepciones de esta palabra llena de trampas, figura una en la que aparece el universo físico enteramente regido por el determinismo, en contraste con la libertad humana, que se caracteriza por la autodeterminación y la creatividad. [...] Es necesario distinguir al menos dos acepciones del término «naturaleza», una en un sentido estricto, y otra, en un sentido más amplio. En su sentido estricto, la naturaleza se opone a cultura y a libertad y se reduce a un orden biológico o a un estado primitivo o salvaje. En el sentido amplio del término, la naturaleza hace referencia, por el contrario, a la esencia global del hombre, y, por supuesto, no solo se incluyen los componentes biológicos de la realidad humana, sino también su modificación en el transcurso de la historia gracias a la libertad creativa de una cultura. Por consiguiente, y en el sentido amplio y propiamente filosófico del término, la libertad y la razón forman parte de la naturaleza humana".

El doctor y catedrático, Emérito de la Universidad Nacional de Educación a Distancia (UNED), Emilio López Barajas Zayas, ratifica y referencia a Leonard (2006: 822) diciendo (2013: 225):

"Los agentes sociales, los ciudadanos, hemos de tener en cuenta que el término "naturaleza" se refiere tanto al mundo físico y a las cosas que se producen en el universo sin intervención humana alguna, como a la esencia de algo, y también al estado primitivo y sin cultivar de un ser vivo o de un lugar donde no se ha alterado su estructura original. La mayoría de los malentendidos acerca del significado de la voz "naturaleza" se deben justamente a la ambigüedad de uso semántico que caracteriza a este término".

Ahora bien, en otro orden de ideas, no podíamos dejar de invitar al dialogo, al doctor y profesor asociado de Psiquiatría en la Universidad de Alcalá y jefe de sección de Psiquiatría del Hospital Universitario de Guadalajara (Guadalajara, España), David Huertas, quien nos comenta que (2008: 40):

"Los sapiens compartimos más del 99\% de nuestro genoma con los chimpancés (Pan troglodytes) y los bonobos (Pan paniscus). Hace unos 6 millones de años nos separamos del tronco común de los chimpancés, mientras que los bonobos se escindieron como especie hace tan sólo un millón de años. Las diferencias observadas en el comportamiento social de estos primates son interesantes para comprender mejor nuestra naturaleza, ya que mostramos rasgos de ambas especies. Los chimpancés comunes se organizan de forma patriarcal y piramidal, imponiendo la jerarquía a través de la violencia. Son irritables y despiadados, tienden a la guerra para defender el territorio, y practican el canibalismo, el forzamiento sexual, y las matanzas grupales indiscriminadas. Por el contrario, los bonobos se reúnen en grupos de estructura matriarcal, cooperativa e igualitaria. Son pacíficos, sociables, sensibles, muy activos 
con el sexo incluyendo las prácticas homosexuales, y toleran la presencia de otros grupos sin tensión. Recientemente, se ha observado que los humanos compartimos con los bonobos los polimorfismos en el gen codificador del receptor para la vasopresina que favorecen la sociabilidad. Como sostiene el reconocido primatólogo Frans de Waal, probablemente caminemos con el legado genético de las dos especies. No se trata de otorgar la razón a Rousseau frente a Hobbes, o viceversa. Ambos estaban en lo cierto. Cada uno descubrió una cualidad esencial de la naturaleza humana. Somos tanto despiadados como sociables, al mismo tiempo que egoístas y altruistas. Que prevalezca lo uno o lo otro depende del contexto social, de la presión del entorno y las dificultades para la supervivencia. Nuestro mundo moderno está despertando al simio dormido en el interior de cada ser humano, al mono desnudo de Desmond Morris. Las condiciones de vida actuales están inclinando la balanza hacia la destrucción de los semejantes más que hacia el amor al grupo".

Ahora bien, evidentemente tanto el entorno socio-cultural de la época, la disciplina con su correspondiente estudio formal e informal, como la postura ideológica, teológica y política, de estos grandes pensadores influyó, en forma determinante, en el desarrollo de su concepción del concepto de "Naturaleza Humana".

Sin intenciones de entrar en la longeva y polémica discusión filosófica, antropológica, epistemológica y teología para extraer, entre la gama de posturas tan disimiles, el concepto más adecuado, o en todo caso, realizar un constructo entre ellas, a fin de obtener la acepción más adecuada de "Naturaleza Humana", el autor de este opúsculo, opta por un acto de temeridad al simplificar su postura en cuanto a dicho concepto y toma como base central y centro de masa de su exposición, el resultado de la hermenéutica reflexiva cristiana (agustiniana) sobre el ser humano, meditación realizada y plasmada en Pensées, la inmortal obra filosófica del polímata, físicos, matemáticos y filósofo cristiano más eminentes de su época y uno de los más grandes escritores místicos en la literatura cristiana, Blaise Pascal (1623-1662), quien con su particular e ingeniosa manera de pensar su religión (filosofía existencialista), nos dice (Pascal \& Havet, 1852: XXVI):

"Ainsi point de surnaturel, point de divin dans l'ordre habituel du monde. Ils n'y voient réellement qu'un seul mystère, celui de l'existence des choses; mais cette existence, une fois donnée, rien ne les étonne ni ne les trouble, car tout leur parait naturel, l'homme aussi bien que l'animal, le vice comme la vertu, la mort comme la vie. Mais pour les yeux de Pascal, le surnaturel est partout: l'homme n'est plus simplement l'homme, il est un monstre, une chimère, moitié Dieu et moitié démon, théâtre d'un combat dont celui de l'Apocalypse n'est que l'image, le combat perpétuel de la grâce et du péché. Toutes les variations que son esprit ou son cœur éprouvent, de la sagesse à la sottise, des bassesses aux sublimités, de la paix au déchirement, ne sont que les vicissitudes de cette lutte des puissances invisibles".

Este insigne personaje proclama que el hombre no es sólo el hombre, él es un monstruo, una quimera, la mitad Dios y mitad diablo, es la imagen de la lucha continua entre la gracia y el pecado, entre la sabiduría y la locura, entre la mezquindad y lo sublime, es un hibrido entre el corazón y la razón, entre el ángel y la bestia.

Esta forma de ver la naturaleza humana, fue heredada por el pensador, jurista, político, historiador y uno de los más importantes ideólogos del liberalismo, convertido en el eco del pensamiento pascaliano, el francés, Alexis Henri Charles de Clérel, vizconde de Tocqueville, conocido como Alexis de Tocqueville (1805-1859). Al respecto, el Excmo. Sr. Don 
Luis Diez Del Corral y Pedruzo en su discurso de ingreso en la Real Academia de Ciencias Morales y Políticas nos dice (1965: 41,42, 100):

"La situación del hombre, que no es todo ni nada, que es un algo entre los dos absolutos del ser y de la nada, se mueve aproximándose y alejándose enrre los dos polos, según que lo considere desde distintos puntos de vista. La imaginación pascaliana ve, de esta suerte, al hombre en un juego de fuerzas adversas, perteneciendo a una y otra, un néant al'égard de l'infinit, un tout al'égard du néant, un milieu entre ríen et tout, un punto al que no define su extensión sino su agilidad. [...] El hombre es para Tocqueville un ser ambiguo por su misma esencia. "El hombre -escribe a Eugène Stoffe's-, con sus vicios, sus debilidades, sus virtudes, su mezcla confusa de bien y de mal, de excelsitud y de bajeza, de honestidad y depravación, es todavía, en su conjunto, el objeto más digno de examen, de interés, de piedad, de afecto y de admiración que existe sobre la tierra".

Y así la imagen singular y paradójica de la condición humana, formulada por Pascal y Tocqueville sobrevivirá en el filósofo y ensayista español, José Ortega y Gasset (18831955), quien califica al ser humano como un centauro de la mitología griega, un ser animal $\mathrm{y}$ a la vez pensante.

Este singular ente, que llamamos homo, tiene una particular naturaleza que lo distingue de todos los seres que hoy conocemos, su singular y única «paradójica dualidad constitutiva»; dos seres integrados, no meramente yuxtapuestos, simplemente, dos seres en uno como tal en su totalidad, ambos radicalmente disímiles, contradictorios y en constante conflicto: por un lado el cuerpo (esclavo de la vida física y las pasiones animales, forjador de peccatorum, sentina de vicios, odios, envidias, desprecio, artimañas y depravación) y por el otro, el espíritu, el alma, el intelecto, la inteligencia, el amor.

Con la idea de fomentar una hermenéutica reflexiva en torno a la "Naturaleza Humana", recordemos las palabras de la doctora y actual profesora de la Catedra de Filosofía Moral del Departamental de Filosofía Moral y Política de la Facultad de Filosofía y Ciencias de la Educación de la Universidad de Valencia y Directora de la Fundación ÉTNOR (ética de los negocios y de las organizaciones), Adela Cortina Orts, en su artículo de opinión en el periódico El País (España) (2012: 29):

"Y la verdad es que tienen razón en afirmar que la posibilidad de desarrollar vicios y también virtudes es consustancial a los seres humanos, pero convendría recordar la lección de aquel jefe indígena que contaba a sus nietos cómo en las personas hay dos lobos, el del resentimiento, la mentira y la maldad, y el de la bondad, la alegría, la misericordia y la esperanza. Terminada la narración uno de los niños preguntó: ¿cuál de los lobos crees que ganará? Y el abuelo contestó: el que alimentéis".

Antes de finalizar este punto es necesario, dejar sobre la mesa, la definición clásica propuesta por Aristóteles según la cual el hombre es un ser vivo dotado de lôgos. La voz de origen griego $\lambda$ ó ${ }^{\circ}$ ऽ «lôgos», ha sido, tradicionalmente traducida al español como razón, principio, inteligencia, pensamiento, pero es principalmente, la palabra en cuanto meditada, reflexionada o razonada, de esta forma, parafraseando al sabio Estagirita, podemos decir que el homo, a diferencia de los animales, es un ser vivo dotado de lôgos. 


\section{Persona}

Son tantas las máscaras que cotidianamente usamos que nos olvidamos quienes somos

Sin la más mínima intención de entrar en la ancestral discusión entre antropólogos, filósofos, teólogos, sociólogos, psicólogos, biólogos y juristas en cuanto a darle respuesta a la pregunta ¿cuál es la acepción más adecuada del término "persona”?, solo orbitáremos alrededor de la superficie a fin de no perder el foco a la invitación y razón de ser de este diálogo, "Est inutilis, non falli, nos sunt qui nos sunt" (Es inútil, no os engañéis, somos lo que somos).

La idea es esclarecer un tanto el panorama en torno a este enigmático término que ha dado mucho que hablar en el mundo intelectual.

Iniciamos diciendo que la locución latina "persōna" deriva de "personare" ("per" intensidad y "sonare" hacer sonidos), se tiene consenso en señalar que probablemente su significado originario proviene del etrusco "phersu" ("máscara del actor", "personaje”) y éste, a

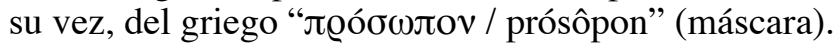

Allende de las clásicas y contemporáneas controversias que circunscriben el término, podemos asegurar que, sin importar la escuela, la disciplina, la especialidad y el pensamiento, el centro de masa de su concepto es la singularidad, es el principium individuationis particular de ese ser a quien le adjudicamos el término "persona" y para ser más específicos sin caer en una tautología, "persona humana".

Indiscutiblemente, la concepción integral de este término nos obliga a desarrollar muchas aristas, tarea que nos alejaría de nuestro objetivo, por lo pronto, nos mantendremos en su origen etimológico ya que a juicio del autor de este opúsculo, el haber usado el vocablo

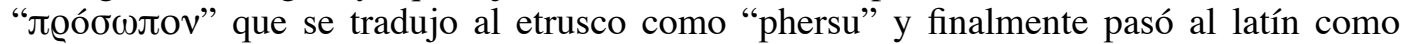
"persōna", respondió claramente la pregunta ¿quién es el individuo?, ¿quién es el sujeto?, en forma simplista es el homo actuando, es el actor enmascarado, es aquel que representa o actúa como alguien, en definitiva es la usurpación de un ser que no le pertenece al ente que lo muestra. Es un engaño forjado en las mismas entrañas de la diosa Maya hindú, cuyo tiempo de vida lo estipula la duración de la trama.

Nicola Abbagnano nos dice que (2010: 810):

"El término Persona significa máscara (en el sentido de personaje: ingl. character; franc. personnage; alem. Rolle; ital. maschera), y precisamente en este sentido fue introducido en el lenguaje filosófico por el estoicismo popular para indicar los papeles representados en la vida por el hombre. Dice Epicteto: «Recuerda que tú no eres otra cosa que actor de un drama, el cual será breve o largo según la voluntad del poeta. Y si a éste le place que representes la Persona de un mendigo, trata de representarla en forma adecuada. De igual modo, si te es asignada la Persona de un cojo, de un magistrado, de un hombre común. Puesto que a ti sólo te corresponde el representar bien a la Persona que se te destina, cualquiera que sea: corresponde a otro el elegirla»".

En total sintonía con el estoicismo (doctrina filosófica fundada a finales del siglo IV a.C. por Zenón de Citio; con una fuerte orientación ética), el término "persona” hace referencia a los diferentes personajes que interpreta el homo en su cotidiano actuar, personajes que no son elegidos al azar, tal como lo señala Epicteto, le corresponde a otro el elegir la máscara que vamos a usar y con ella, el personaje que vamos a interpretar.

Desde el punto de vista estoico, en la vida cotidiana, el "otro" señalado explícitamente por Epicteto, no es un ser, es más bien la suma holística de cadenas complejas de causas que 
dan como effectus (efecto) fenomenológico, la asignación de la máscara a usar y por ende el personaje a interpretar, de hecho, la relación entre homo y máscara es simplemente una relación de causa y efecto, de motivo y acción, de acción y reacción.

En este punto está claro que el ser de la persona es distinto del ser del ente que lo intenta personificar, esta voluntad de aparentar ser lo que no es, es una tarea que implica trabajo, esfuerzo, dedicación y constante monitoreo, con sus continuos ajustes, a fin de lograr y mantener una fiel interpretación (encarnación) del personaje asignado.

¿No sería más cómodo, natural y sencillo, desprenderse del hechizo seductor egocentrista de la diosa Maya hindú, y así, no usar la máscara y ser el ser inmanente de su singular ente en cuanto tal? ¿No sería más honesto y responsable, no tener reparo en reconocer su propia esencia y mostrarse como mera representación de una conciencia (Bewußtsein), sin atajos ni triquiñuelas, sin maquillaje ni aditivos, ser simplemente, el Homo Sapiens que se es, como acto transcendental subordinado a su libertad de la voluntad y su destino?

Este estoico pensamiento representa la punta del iceberg de este opúsculo, por lo que se considera sustancial tenerlo presente ya que a medida que avancemos en este diálogo, visualizaremos su veracidad y pertinencia.

\section{Mentira}

Puedo decir algo falso, de toda falsedad y no mentir; aun siendo falso, ese algo que digo, lo digo con toda mi verdad, por ende, no estoy mintiendo. En un acto intencional de mentir, en su stricto sensu, aun profiriendo la verdad, puedo estar mintiendo.

Ramón García-Pelayo y Gross en su diccionario Pequeño Larousse Ilustrado (1993: 675), hace uso de dos acepciones para definir el verbo Mentir (mentiri). En la primera, se alude a un acto de comunicación: afirmar lo que se sabe que es falso. En la segunda, se señala en forma indirecta una intencionalidad: inducir a error. Y al definir Mentira (mendacium), en su primera acepción nos dice que es un discurso contrario a la verdad con ánimo de engañar. A juicio del autor de este opúsculo, esta definición sintetiza y esboza las dos variables indispensables que caracterizan toda mentira: comunicación (lenguaje) y la intencionalidad.

Al respecto, en el 2002, Dolores Madrid Vivar en su tesis doctoral (inédita) con el nombre "La mentira infantil: diagnóstico e intervención psicopedagógica" en la Universidad de Málaga, Facultad de Ciencias de la Educación, Departamento de Métodos de Investigación e Innovación Educativa, dirigida por la Dra. Angeles Gervilla Castillo y la Dra. Emelina López Gónzalezen, nos dice que (Madrid Vivar, 2002) dos de las más recientes definiciones de "Mentir", la de Alonso-Quecuty y Hernández-Fernaud y la de Sotillo y Riviere, tienden a conceptualizar, dicho verbo, en relación al proceso de comunicación y al lenguaje respectivamente.

Partiendo de la hipótesis que al repetir varias veces las declaraciones verdaderas y las falsas, con el tiempo, dichas declaraciones variarían, y usando las técnicas de evaluación e interpretación de la información involucrada un proceso dinámico de comunicación dadas por Arne Trankell (1972), Marisa Alonso-Quecuty \& Estefanía Hernández-Fernaud realizaron un experimento (la muestra estuvo compuesta de 32 sujetos) donde registraron pautas evolutivas distintas en la verdad y mentira (señaladas en la secuencia repetitiva de declaraciones), logrando demostraron su hipótesis inicial (Alonso-Quecutya \& HernándezFernauda, 1997).

Por otro lado, encontramos el experimento realizado por María Sotillo Méndez y Ángel Rivière Gómez (2001) donde se analizó la mentira como una manifestación lingüística del mentiroso y su comportamiento adaptativo al usarla como instrumento social.

En ambos experimentos quedó claramente evidenciado que la mentira es un acto de co- 


\begin{tabular}{|c|c|c|c|}
\hline $2+10 x=3$ in & 121411 & starnit. $8 \times 11$ & 17ant \\
\hline Armentia (1956) & 7. 8 años & Perner $(199)$ & 4 aก๊os \\
\hline Durandin (1958) & 6 แ 8 años & Ekman (1991) & $3-4$ años \\
\hline Torres (1962) & 7 anios & Leekman (1991) & 3 y medio- 4 anlos \\
\hline Bakwin \& Bakwin (1974) & 5 años. & Leung, Robson \& Lim (1992) & $5-8$ años \\
\hline Berge y volhs. (1976) & $6-8$ ànos & Astington (1998) & 4 an้อง \\
\hline Bascou $(1978)$ & 6 años & Halperi (2000) & 2 à่os \\
\hline Peterson, Peterson \& Seeto (1984) & 3 años & Tison (2001) & $9 \cdot 10$ añอง \\
\hline Piaget (1983) & $7 \cdot 8$ afíos & Moya (1993) & 5 มกิดร \\
\hline Mazet \& Houzel (1981) & 6-7 años & Blidner (2002) & 7 aก๊os \\
\hline Stouthumer-Locber (1986) & 3 años & Maguarre (2002) & 8 años \\
\hline Lewnk, Stangery Sullivan (1989) & 3 años & Wood (UMDN, 2002) & $2-3$ anิดล \\
\hline
\end{tabular}

Tabla 1: ¿A qué edad empieza el Niño a Mentir? Fuente: Madrid Vivar, 2002: 173.

municación social intencional y el lenguaje (hablado) cumple un rol protagónico en dicho acto.

Ahora bien, ¿cuándo el Homo comienza a mentir?, para responder esta pregunta, Dolores Madrid Vivar, en su tesis, haciendo referencia a varios expertos en la materia nos dice (Madrid Vivar, 2002):

"Para Lawrence E. Shapiro los niños dicen mentiras casi desde que comienzan a hablar, incluso antes.

Considera Janet Wilde Astington que a los 4 años los niños comienzan a mentir deliberadamente y pueden engañar a otras personas forjando creencias falsas en el otro.

Paul Ekman es el autor más representativo de esta postura afirmativa de que el niño miente y en su libro “¿Por qué mienten los niños?” indica que los niños son capaces de mentir a una edad mucho más temprana de lo que los adultos creen. A los 4 años, y quizás antes, algunos niños saben mentir, y de hecho lo hacen. No es que se estén equivocando, ni confundiendo la fantasía con la realidad, sino que están intentando deliberadamente engañar.

Eugene Halpert, que explora la mentira y su relación con la estructura intrapsíquica y su desarrollo, puntualiza que las habilidades cognitivas y el aparato psíquico tienen que desarrollarse hasta el punto que el niño pueda diferenciar "sí mismo" y objeto, y estar presente un prototipo de Super-Yo para que se pueda mentir. Aunque pueda resultar alarmante, sitúa la capacidad de empezar a mentir entre los 16 y los 24 meses de edad".

El autor de este opúsculo le pide disculpas a Shapiro y Halpert ya que considera que el niño antes de hablar, apela al engaño, a la simulación, la finta para producir lo falso, pero no miente, para mentir hay que saber hablar o en todo caso, saber escribir sin olvidar, la dimensión intencional y moral, inmanente en la mentira.

En cuanto a la dimensión moral, Jean Piaget nos dice (1984) que el niño es amoral hasta los 2 años de edad, pocos meses después (alrededor de los dos años y medio) es cuando vemos, en estado puro, el realismo moral y la responsabilidad objetiva, por ende, difícilmente un niño con edad inferior a dos años, siendo amoral y sin saber hablar, difícilmente podrá esgrimir una mentira.

Desafortunadamente la respuesta a la interrogante ¿a qué edad empieza el niño a mentir? 
no tiene el consenso de los expertos en el tema y así, Dolores Madrid Vivar nos muestra una lista cronológica de varios especialistas que han tratado de responder la interrogante planteada.

De acuerdo con la Tabla 1, el promedio de edades circunda alrededor de los 5 años y medio, pero indiferentemente de la edad que pueda tener el niño cuando dice su primera mentira, este opúsculo pretende resaltar que desde el instante en que el homo (en su niñez) esgrime su primera mentira hasta llegar a su expiración, su capacidad de mentir, auspiciada por el cumulo de experiencias adquiridas desde su estadía en el útero hasta llegar aproximada a los 12 años de edad, va evolucionando acorde con dichas experiencias, es decir, desde que el homo es un feto hasta la edad de 12 años, cual esponja, absorbe todas sus experiencias con el medio ambiente, con su padres y familiares, con su mascota y amiguitos, maestras y conocidos, estas enseñanzas son absorbidas por el consciente y cual marca indeleble, quedan registradas de por vida en el inconsciente. De esta forma, su capacidad de mentir, regidas por estas experiencias, va evolucionando a todo lo largo de sus etapas de desarrollo como ser humano (niñez, adolescencia, juventud, adultez, vejez).

De esta forma, la educación, los principios morales y éticos, los sentimientos de amor, equidad, compañerismo y filantropía, entre otros, así como los sentimientos de odio, rencor, desprecio, envidia, avaricia, lujuria, rechazo, soledad, schadenfreude, que experimentamos y evidenciamos en nuestras etapa prenatal, lactancia, infancia y niñez, nos marcan para el resto de nuestra existencia dándole forma, color y textura a las mentiras que desarrollaremos durante nuestras vidas.

\section{Verdad}

"Decir que lo que es, no es o que lo que no es, es, es falso, y decir que lo que es, es y que lo que no es, no es, es verdadero". Aristóteles. Metaphysica, IV.

En el otro extremo tenemos la contraparte de la mentira, la "verdad", término sorprendentemente escurridizo y controvertido, nada fácil de conceptualizar, de hecho, en los múltiples intentos por definirlo se han desarrollado un número considerable de teorías de la verdad como la correspondencia y relación, la coherencia, como revelación, como redundancia, la teoría desentrecomilladora, entre otras.

Juan Antonio Nicolás Marín y María José Frápolli Sanz en su artículo "Teorías actuales de la verdad" desarrollan una excelente caracterización de los diferentes tipos de teoría de la verdad, a continuación tomamos prestado el listado de ellas (1997: 154,155):

Teorías de la correspondencia.

Teorías semánticas.

Teoría lógico-semántica: A. Tarski.

Teoría semántico-formal: E. Tugendhat.

Teoría semántico-fundamental: P. Hinst.

Teoría semántica del realismo interno: H. Putnam.

Teoría semántico-naturalista: W.v.O. Quine.

Teoría semántico-esencialista: S. Kripke.

Verdad como primitivo semántico: D. Davidson.

Teorías no semánticas.

Teoría de las condiciones de la correlación: J. Austin.

Teorías lógico-empíricas: B. Russell y 1 Wittgenstein, R. Carnap.

Teorías dialéctico-materialistas: K. Marx, A. Schaff, M. Horkheimer

Teorías pro-oracionales: Ramsey, P.F. Strawson, D. Grover, CJ.F. Williams. 
Teorías fenomenológicas.

Teoría evidencial: E. Husserl, F. Brentano.

Teoría perspectivista: J. Ortega y Gasset.

Teoría metafórica: P. Ricoeur.

Teoría de la verdad real: X. Zubiri.

Teorías hermenéuticas de la verdad.

Teoría hermenéutico-ontológica: M. Heidegger.

Teoría existencialista: K. Jaspers.

Teoría lingüístico-histórica: H.G. Gadamer.

Teoría hermeneútico-práctica: M. Foucault.

Teoría hermenéutica-lingüística: J. Simon.

Teorías coherenciales.

Teoría lógico-empírica: O. Neurath y C. Hempel.

Teoría criteriológica: N. Rescher,

Teoría coherencial-sistemática: L.B. Puntel.

Teorías pragmáticas de la verdad.

Teoría pragmático-funcionalista: W. James.

Teoría pragmático-correspondentista: Ch.S. Peirce.

Teoría ético-pragmática: S. Haack.

Teoría hermenéutico-relativista: R. Rorty.

Teoría histórico-práctica: Ellacuría.

Teorías intersubjetivista.

Teoría consensual: K.O. Apel y J. Habermas.

Teoría dialógica: K. Lorenz, P. Lorenzen-W. Kamlah.

No es nuestro objetivo entrar en detalles técnicos de cada una de ellas pero si recomendarles su lectura y análisis.

El autor de este opúsculo se aferra al sentido originario, etimológico, del término "verdad", vocablo cuyo origen proviene de la voz griega $\dot{\alpha} \lambda \hat{\eta} \theta \varepsilon \iota \alpha$ «alétheia» y ésta a su vez, con la privación $\alpha$ (a) del verbo griego $\lambda \alpha v \theta \alpha ́ v \omega$ «lanthanō» que significa: pasar inadvertido, el que es difícil de notar o el que está o permanecer oculto. De esta forma, verdad es el descubrimiento de la cosa, es decir, es ver lo que la cosa es, es desvelar el ser del ente como tal.

Ya Heidegger en su conferencia "De la esencia de la verdad" (1952) lo afirmaba explícitamente: la esencia de la verdad es, simplemente, la verdad de la esencia, es decir, la verdad del ser y para despejar dudas, aclara diciendo que no se trata de la formulación de una paradoja y tampoco una simple inversión del orden de las palabras. La esencia de la verdad es la verdad del ser, pero no es cualquier ser, es lo que Heidegger denomina Sein, el ser del Da-sein (apertura o desocultación originaria).

«Da-sein es la permanencia del hacerse presente de la verdad del ser (Seyn). Desarrollo del carácter del Da (Daheit), propio del Da como fundamentación del Da-sein. El Da se hace presente y haciéndose presente ha de ser aceptado en el ser (Sein) del Da-sein». «Da» indica, pues, la apertura o la verdad originaria del ser, que fundamenta la presencia y la permanencia del ser (Dasein). [...] «La pertenencia al ser (Seyn) está presente sólo porque el ser (Sein) en su unicidad necesita el Da-sein; y fundado en él y fundándolo necesita al hombre. De otro modo no hay presente verdad alguna». El hacerse presente del ser (Seyn, gen. subj.) se hace presente como ser (Sein), como verdad o apertura del ser (gen. objet.) (Berciano, 1992: 446).

Por otro lado, Miguel Angel Nuñez en su artículo "El concepto de verdad en sus dimensiones griega y hebrea", nos dice que $(1997: 48,49)$ "la idea griega de verdad carece de carácter histórico. [...] La verdad alétheia no acontece, es". Aseveración que está en clara y evidente discordancia con el pragmatismo de William James quien partiendo de la 
noción de adecuación, asegura que la verdad es un proceso cuyo resultado es la adecuación a la realidad, adecuación llevada a tal extremo que afirma que toda verdad tiene vida, nace y envejece (Rodríguez, 1990), pero encontramos otro pragmatista clásico, un tanto más extremista, Ferdinand Cunning Scott Schiller, quien asegura que tanto la realidad como la verdad son plásticas, están hechas por el hombre y son relativas a los propósitos privados de una persona particular. La verdad depende de nosotros y es mutable, al igual que la realidad (Barrena, 2014).

Bien, dejando de lado la clásica postura pragmática, que a juicio del autor de este opúsculo, confunden "verdad" con "certeza", confusión que tuvo en sus orígenes una marcada influencia, por un lado el pensamiento aristotélico, veritas est adaequatio rei et intellectus, est adaequatio intellectus ad rem y por el otro, el Discurso del método para dirigir bien la razón y hallar la verdad en las ciencias (Discours de la méthode pour bien conduire sa raison, et chercher la vérité dans les sciences), obra magistral de René Descartes (Renatus Cartesius). Al respecto Rogelio Rovira Madrid nos dice (2009: 672):

"Para la tradición aristotélica, en efecto, la verdad se dice fundamentalmente de dos maneras: como verdad lógica o, acaso mejor, del conocimiento (veritas intellectus) y como verdad ontológica o de las cosas (veritas rei); es decir, como adecuación del entendimiento con las cosas y como adecuación de las cosas con el entendimiento".

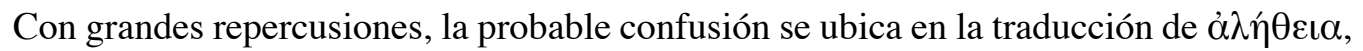
al latín como "veritas", nombre común usado para referenciar la virtud romana de la veracidad (o sinceridad), al respecto, el discípulo de Heidegger, Hans Georg Gadamer en su obra Verdad y Método II, nos dice (1998: 54):

"Si la verdad (veritas) supone la verificabilidad -en una u otra forma-, el criterio que mide el conocimiento no es ya su verdad, sino su certeza. Por eso el auténtico ethos de la ciencia moderna es, desde que Descartes formulara la clásica regla de certeza, que ella sólo admite como satisfaciendo las condiciones de la verdad lo que satisface el ideal de certeza".

Ahora bien, para tener una veritas, necesariamente se tuvo que dar una alétheia y no al revés, de tal forma que podríamos decir que la veritas es la alétheia verificada ya que la verificación (Bewährung), como tal, parte de una verdad que de alguna manera fue poseída. La verificación, la justificación del juicio recae sobre su verdad investida, descubre ciertamente su rectitud, su conformidad con lo juzgado. Tal es la función de la evidencia: no es la verdad misma, es propiedad de una verdad cualificada "alétheia" (Ceñal Lorente, 1950).

Volviendo a alétheia, la verdad originaria, la verdad ontológica, entendida ésta por Heidegger, no como verdad del ser real en sí, sino como verdad de revelación del ser (Ceñal Lorente, 1950), ser que debe ser arrebatado del estado de ocultación y encubrimiento, siendo éstos propios de la acción y del lenguaje humano. Porque el lenguaje humano no expresa sólo la verdad, sino la ficción, la mentira y el engaño. Hay, pues, una relación originaria entre el ser verdadero y el discurso verdadero. La desocultación del ente se produce en la sinceridad del lenguaje, en la sinceridad del lôgos (Gadamer, 1998), de hecho la alétheia solo se desvela, solo se muestra ante un percibir en el lôgos.

Cuando usamos el término "lôgos", por su carácter polisémico, nos referimos a un número considerable de significados: razón, principio, inteligencia, pensamiento, lenguaje (la palabra en cuanto meditada, reflexionada o razonada), hermenéutica, en fin, no solo pensamos en la palabra y su aspecto lingüístico - semántico, también, a partir del aspecto cognitivo involucrado, trascendemos el sensus literalis y pensamos holísticamente en el 
contenido. Este cogito holístico (fenomenológico, diría Husserl (1960), irremediablemente nos remite como mínimo a la comprensión, entendimiento, interpretación, objetividad, prejuicios, sesgos, experiencia, hermenéutica, etc. Términos estos que cuentan con una longeva y extensa carga histórica, filosófica, semántica, etc., etc., que a todas luces nos advierten de nuestras limitaciones y nos recuerdan que la verdad solo se muestra a solicitud del lôgos, de tal forma que la verdad que se desocultará estará limitada por el lôgos que la implora, por ende, ninguno de nosotros, por nuestra condizione umana, puede abarcar la totalidad de la verdad como tal.

Ya Protágoras lo aseveraba «el hombre es la medida de todas las cosa» (Laercio, 1792; Platón, 1988), homo omnium rerum mensura est, y así, la verdad depende, en suma, de los fines y circunstancias del locutor, del que habla, y aún de la audiencia al cual se dirige, en definitiva, la verdad termina siendo algo totalmente relativo (Nuñez, 1997).

\section{Disertación}

Hablamos de la "Naturaleza Humana", de la "Persona", la "Mentira" y la "Verdad", resaltamos la importancia de la voz. de origen griego $\lambda o ́ \gamma o \varsigma$ «lôgos» y creemos que se evidenció lo proclamado en el título de este opúsculo, "Est inutilis, non falli, nos sunt qui nos sunt" (Es inútil, no os engañéis, somos lo que somos).

De acuerdo con la naturaleza humana, el homo es como lo clasificaba José Ortega y Gasset, un centauro de la mitología griega, un ser animal y a la vez pensante, como diría Aristóteles, somos monos desnudos dotatos de lôgos (razón, principio, inteligencia, pensamiento, lenguaje, comprensión, entendimiento, interpretación, objetividad, prejuicios, sesgos).

Sin ninguna duda, creemos firmemente que la actual pobreza, corrupción, desempleo, hambre y desnutrición, desintegración familiar, delincuencia, calentamiento global, calidad de aguas superficiales, la guerra, la violencia de género, el racismo, la concentración del poder en manos de unos pocos privilegiados, la drogodependencia, la obsesión por la estética, el consumismo excesivo, la inmigración, discriminación social, terrorismo, politiquería, etc., etc., nos señala, sin ningún prejuicio o sesgo, que debemos olvidarnos de la postura romántica, de la imagen idílica del bonum hominis que tanto salvaguardó Rousseau, y aceptar nuestra condición hibrida, corazón - razón, sabiduría - locura, amor - odio, ángel - bestia, somos lo que somos y no lo podemos evitar.

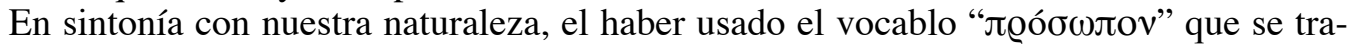
dujo al etrusco como "phersu" y finalmente pasó al latín como "persōna", para responder la pregunta ¿quién es el individuo?, ¿quién es el sujeto?, ¿quién soy?, la elección de dicho vocablo, no pudo ser más acertada ya que nos define muy bien.

Pelayo García Sierra en su Diccionario filosófico (2000) nos dice que la misma etimología de la palabra latina "persōna" demuestra que es un concepto sobreañadido al concepto de hombre. Un refrán de origen jurídico, también lo recuerda: homo plures personas sustinet, es decir, el hombre desempeña muchas funciones, se reviste con diferentes máscaras, actúa como empresario y delincuente, es padre e hijo a la vez, es benefactor y explotador, es estudiante y profesor.

Ahora bien, cuando hablamos de máscara, personaje, actor, rostro, en forma sutil e imperceptible, se tiende a sinonimizar persona con homo, siendo dos términos con una clara diferencia: persona es un homo, actuando. "Ea persona" puede significar "homo", pero teniendo en cuenta el papel, calidad y posición que ocupa (Tamayo y Salmorán, 1986).

En el ciclo de vida del homo, a todo lo largo de sus etapas de desarrollo como ser humano, a partir de su niñez hasta la vejez, va mejorando en la selección de las máscaras a usar, 
sobretodo y en forma más evidente, en su desarrollo profesional, en su recorrido en los niveles jerárquicos en la empresa va cambiando de máscara en la medida que se va adaptando en los nuevos cargos (analista, supervisor, gerente, directivo).

Quizás, el uso común y frecuente de las máscaras, en la mayoría de las veces, es producto de lo que Sartre denominó "mauvaise foi" (mala fe), tal vez, esa necesidad de simulación sea para satisfacer nuestro ego o para salvaguardarnos de nuestros enemigos, probablemente el entorno, la sociedad en donde nos desenvolvemos, junto con nuestro lôgos, nos dictan directrices en el uso de las máscaras o en última instancia, se reducen a algo natural: la simple sobrevivencia.

La que sí tiene una relación directa con la sobrevivencia es la "mentira", patrimonio exclusivo de los homininos (seres humanos), nació poco después que el primer homo comenzó a hablar, de hecho lo evidenciamos en los niños, Jacques Laroche (citado en Ajuriaguerra, 1996) afirma que poco despues de los tres años, el niño inicia con el aprendizaje de la mentira, cuya adquisición es de una importancia determinante en su evolución psicológica.

En cuanto al mentir, Joaquín $\mathrm{M}^{\mathrm{a}}$ Aguirre Romero (2007) nos comenta que nosotros, los seres humanos hemos logrado hacer de la mentira el elemento más refinado de la evolución, convirtiéndola en un arma evolutiva ofensiva y defensiva. Nosotros los homininos, mentimos por enfermedad, por necesidad, por utilidad o simplemente, por placer. Pero, sobre todo, mentimos porque somos humanos.

En el reino del engaño de la diosa Maya hindú, la producción de lo falso tiene muchos rostros, uno de ellos, la hija de la necesidad, la mentira. De acuerdo con Andrew Whiten, y Richard William Byrne (1988) la mentira es un engaño del tipo táctico, ya que éste es pensado y mal intencionado.

Para mentir necesariamente se deben cumplir dos condiciones sine quibus non: la palabra en cuanto meditada, reflexionada o razonada "lôgos" y la intencionalidad de la consciencia, de no cumplirse una de las dos condiciones, pudiéramos estar hablando de una de las hermanas de la mentira: la manipulación, la finta, la omisión, el disimulo, la hipocresía, la simulación, el cripsis (camuflaje), el aposematismo (señales de advertencia destinadas a alejar a su depredador), en fin, diversas formas miméticas, cual Thaumoctopus mimicus (pulpo mimético) con el fin de engañar al otro.

Ahora bien, el emitir una mentira (constructo cognitivo-social), exige un esfuerzo, un trabajo intelectual, psicológico cognitivo previo. Por intuición, todos sabemos que decir la verdad es más fácil que decir mentiras, por ende, nos auto-mentimos (auto-engañamos) a fin de creernos la mentira, para así entonces, mentir más eficazmente.

Al respecto, Benjamín Domínguez Trejo nos dice:

"el cerebro requiere desplegar un mayor esfuerzo para mentir que para decir la verdad. El engaño y la simulación fundamentalmente involucran la supresión deliberada y vigorosa de las respuestas verdaderas; es decir, los consejos populares de las abuelas que aconsejaban: "cuando dudes de algo di la verdad", sugieren que practicar la verdad es obviamente mucho más fácil que mentir. Y aunque en muchos estudios científicos aún no se delimita todavía qué tanto contribuyen los efectos de la ansiedad en estos cambios en la actividad cerebral, el hecho es que la corteza cingular anterior está relacionada con el procesamiento emocional de manera que no hay modo de estar seguro si el aumento de la actividad en estas áreas es una firma cerebral de la mentira o simplemente de un aumento en el nerviosismo al mentir. Hasta estos días, la mayoría de nosotros podernos conservar y disfrutar un buen grado de tranquilidad, porque en realidad nadie puede leer nuestras mentes o corazones. En otras palabras, todavía no existe una tecnología que pueda hacer que las mentiras sean obsoletas" (Domínguez Trejo, 2004: 17). 
En efecto, el darle forma, color y textura a ese constructo cognitivo-social que llamamos "mentira", se requiere un mayor número de actividades cerebrales, en comparación, si solo dijéramos la verdad. Este hecho ha sido comprobado científicamente tal como lo evidencian los resultados de la prueba Guilty Knowledge Test (GKT) realizada por Daniel Langleben y siete de sus colaboradores del departamento de Psychiatry y el de Radiology de la Universidad de Pennsylvania, Langleben nos comenta (2002) que una asociación entre el cerebro y las potenciales respuestas y mentiras en el GKT sugiere que el engaño puede estar relacionado con cambios en la actividad cerebral, cambios que pueden ser anatómicamente localizados con imágenes de resonancia magnética funcional (fMRI). El nivel de oxigenación de la sangre (oxihemoglobina - desoxihemoglobina) difiere entre las respuestas engañosas y las verdaderas, dicho contraste (blood oxigen level dependency) fue medido con un escáner de 4 Tesla y analizado mediante el mapeo paramétrico estadístico en 18 participantes que realizaron el GKT (ver Figura 1).

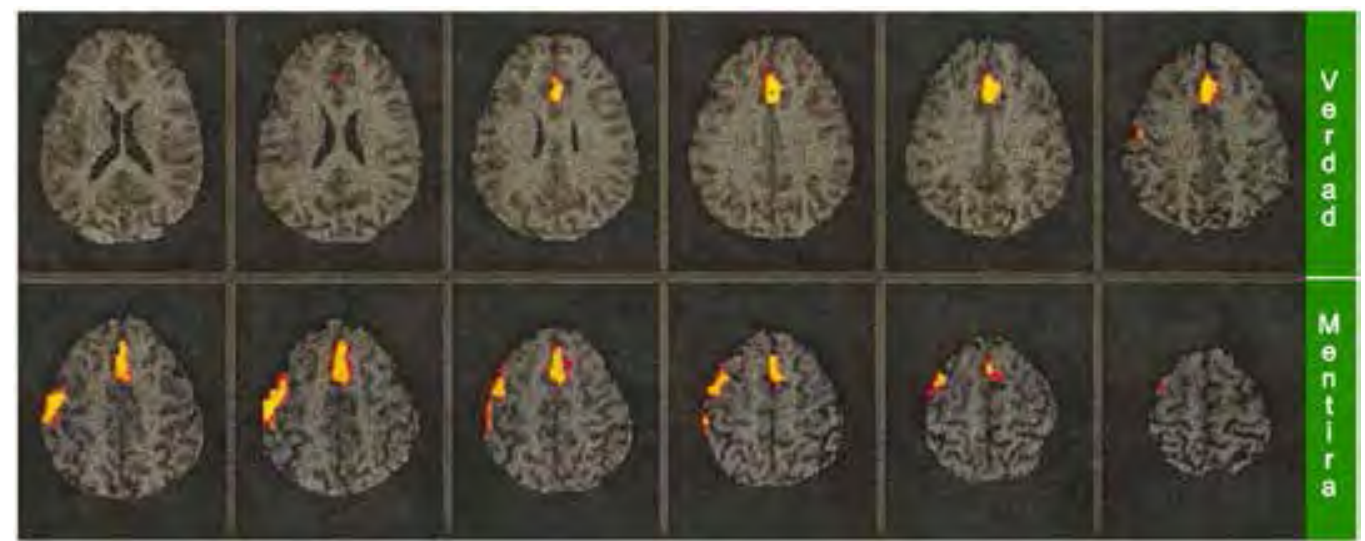

Figura 1: Imágenes de resonancia magnética funcional (fMRI) midiendo el contraste de blood oxigen level dependency para detectar la mentira.

Fuente: Langleben, y otros, 2002: 728.

En la Figura 1 se aprecia claramente que en la mentira hay mayor actividad, incluso se observan imágenes que muestran la inhibición de determinados circuitos neuronales que impida la transmisión de la verdad.

Ahora bien, a pesar que la mentira implica un mayor esfuerzo, no solo para prepararla y enunciarla, pero sobre todo, para mantenerla en el tiempo, a pesar que la verdad, debería ser más fácil y natural, el homo opta por el camino más tortuoso y difícil, sin ver a los lados, se aboca y esmera en su proyecto de mentira, cual príncipe de Maquiavelo en acción.

El príncipe, de acuerdo con Maquiavelo, debe tener capacidad para manipular situaciones, ayudándose de cuantos medios precise mientras consiga sus fines: ciò che conta è il risultato, non importa il mezzo per raggiungerlo (lo que vale es el resultado, no importan los medios para lograrlo). Debe ser hipócrita y diestro en el engaño, y no, necesariamente, debe poseer virtudes, sólo aparentarlas. Debe borrar la palabra ética de su diccionario, debe ser una persona amoral, indiferente ante bonum et malum (el bien y el mal), debe estar por encima de ambos (Tarantino-Curseri, 2015: 179).

Como contraparte de la mentira, hablamos muy someramente de la "verdad" y vimos que en los múltiples intentos por definirla se desarrollaron un número considerable teorías que intentan conceptualizarla, sin embargo, se optó por el sentido originario, etimológico, del término cuyo origen proviene de la voz griega $\alpha \lambda \eta ́ \hat{\theta \varepsilon \iota} \alpha$ «alétheia», es ver lo que la cosa es, es desvelar el ser del ente como tal y vimos que ésta solo se desvela, solo se muestra ante un percibir en el lôgos. 
Efectivamente, la alétheia puede estar delante de nosotros, la podemos ver (implica percibir o conocer a través del sentido de la vista, solo se necesitan ojos, en buen estado físico, y evidentemente el cerebro) pero no la miramos (con el mirar, se hace presente la intención de ver, se toma la decisión de enfocar hacia lo que se quiere descubrir, hacia lo que se quiere desvelar) y mucho menos la observamos (para observar, primero debemos ver, luego mirar y ambos verbos envueltos en el lôgos).

Evidentemente para poder desocultar la alétheia (para conocer la verdad) se debe dar una conditio sine qua non, la observación, y ésta a su vez, requiere taxativamente, del lôgos, por ende, las dimensiones y calidad de nuestro lôgos define las dimensiones de la alétheia que vamos a desvelar como tal.

La alétheia, es la alétheia como tal, no depende del lôgos, pero el lôgos si establece la cantidad, el trozo de alétheia que vamos a desvelar. Nunca podremos desocultar la alétheia total, la totalidad de ésta, le pertenece solo a Dios, nosotros los mortales, los homininos solo tenemos acceso a una parte de ella, las dimensiones de la parte lo establece taxativamente nuestro lôgos.

A manera de conclusión, en todo lo concerniente a la Naturaleza Humana, la Persona, la Mentira y la Verdad, el lema conductor debería ser "usemos el plural del «yo» (nosotros), coloquemos el acento en el «NOS» de «NOSotros» y humanizemonos para no extinguirnos".

Es inútil, no os engañéis, tanto la Naturaleza Humana, la Persona y la Mentira, junto con la dificultad de desvelar la Verdad, han fortalecido, desde los tiempos remotos, la hegemonía del homo economicus, exaltando el "yo" y convirtiendo el "nosotros" en una simple flatus vocis, con una clara pretensión demiúrgica en pro de instituir la era poshumanista.

La única forma de superar su envestida es reemplazando el singular «yo» por su plural «nosotros», y fortaleciendo, al máximo posible, el lôgos.

Por favor, estudia, estudia y sigue estudiando, cuando fallezcas tendrás tiempo para descansar, pero mientras estés vivo, estudia e investiga para fortalecer tu lôgos, no solo por tu bienestar, es por el bienestar de todos, todos-nos-otros.

"Lo bueno" puede ser suficiente para algunos. Pero nosotros, los trabajadores del Conocimiento, debemos buscar "lo excelente" y nunca, pero nunca, conformarnos con menos.

\section{Bibliografía}

Abbagnano, N. (2010). Diccionario de filosofía (Cuarta Edición ed.). (J. E. Calderón, G. A. N., E. C. Tapie Isoard, B. González Casanova, \& J. C. Rodríguez, Trads.) México, D. F.: Fondo de Cultura Económica.

Aguirre Romero, J. M. (2007). Sobre lenguaje, mentiras y otros avances evolutivos. Logos. Revista de la Facultad de Filosofía y Humanidades de la Universidad de La Salle(11), 34-42. Recuperado el 6 de Mar de 2016, de http://revistas.lasalle.edu.co/index.php/lo/article/ view/1551/1427

Ajuriaguerra, J. (1996). Manual de psiquiatría infantil. (A. Rego, Trad.) Barcelona, España: Masson S. A.

Alonso-Quecutya, M., \& Hernández-Fernauda, E. (1997). Tócala otra vez Sam: repitiendo las mentiras. Estudios de Psicología, 18(57), 29-37. doi:10.1174/021093997320972025

Ávalos Tenorio, G. (2001). Leviatán y Behemoth. Figuras de la idea del Estado. Coyoacán, México: Universidad Autónoma Metropolitana.

Barrena, S. (2014). El pragmatismo. Factótum. Revista de Filosofía, 12, 1-18. Recuperado el 6 de Mar de 2016, de http://www.revistafactotum.com/revista/f_12/articulos/Factotum_12_1_ Sara_Barrena.pdf

Berciano, M. (1992). ¿Qué es realmente el Dasein en la filosofía de Heidegger? Themata: Revista de Filosofía(10), 435-450. Recuperado el 6 de Mar de 2016, de https://idus.us.es/xmlui/ bitstream/handle/11441/27244/file_1.pdf?sequence=1 
Calvo de Saavedra, Á. (2012). El carácter de la "verdadera filosofía” de David Hume. Bogotá, Colombia: Pontificia Universidad Javeriana (Colección Laureata).

Ceñal Lorente, R. (1950). El problema de la verdad en Heidegger (conferencia en el Primer Congreso Nacional de Filosofía en la Universidad Nacional de Cuyo (Mendoza, Argentina)). Sapientia. Revista de la Facultad de Filosofía y Letras de la Pontificia Universidad Católica Argentina, 5(15), 19-40. Recuperado el 6 de Mar de 2016, de http://bibliotecadigital.uca. edu.ar/repositorio/revistas/sapientia15.pdf

Cortina Orts, A. (2 de Jul de 2012). Ética en tiempos de crisis. Periódico EL PAÍS (España): 29. Recuperado el 6 de Mar de 2016, de http://elpais.com/elpais/2012/06/13/opinion/1339587064_162579.html

del Corral, L. D., \& García Valdecasas, A. (1965). Discurso de ingreso en la Real Academia de Ciencias Morales y Políticas. La mentalidad política de Tocqueville con especial referencia a Pascal (págs. 7-146). Madrid: Real Academia de Ciencias Morales y Políticas. Recuperado el 6 de Mar de 2016, de http://www.racmyp.es/R/racmyp/docs/discursos/D17.pdf

Domínguez Trejo, B. (2004). El Estudio de las Mentiras Verdaderas. Reseña sobre abuso con el polígrafo. México D. F., México: Comisión Nacional de los Derechos Humanos.

Gadamer, H.-G. (1998). Verdad y Método II. (M. Olasagasti, Trad.) Salamanca, España: Ediciones Sígueme.

García Sierra, P. (2000). Diccionario filosófico. Manual de materialismo filosófico. Una introducción analítica. Oviedo, España: Fundación Gustavo Bueno. Recuperado el 6 de Mar de 2016, de http://www.filosofia.org/filomat/df278.htm

García-Pelayo y Gross, R. (1993). Pequeño Larousse Ilustrado. Buenos Aires, Argentina: Larousse.

Heidegger, M. (1952). De la esencia de la verdad. Revista Cubana de Filosofía, 2(10), 5-22. Recuperado el 6 de Mar de 2016, de http://www.filosofia.org/hem/dep/rcf/n10p005.htm

Huertas, D. (2008). El futuro de los sapiens en nuestras manos. Ars Medica. Revista de Humanidades, 7(1), 37-53. Recuperado el 10 de Mar de 2016, de http://www.revistadehumanidades. es/revista/v7n1/el_futuro_de_los_sapiens_en_nuestras_manos.pdf

Hume, D. (1988). Tratado de la naturaleza humana: Ensayo para introducir el método del razonamiento experimental en los asuntos morales. (D. Félix, Trad.) Madrid, España: Tecnos.

Husserl, E. (1960). Cartesian Meditations. An Introduction to Phenomenology. (D. Cairns, Trad.) The Hague. The Netherlands: Martinus Nijhoff Publishers.

Laercio, D. (1792). Los Diez Libros de Diógenes Laercio Sobre las Vidas, Opiniones y Sentencias de los Filósofos más Ilustres. (J. Don Ortiz y Sanz, Trad.) Madrid, España: Imprenta Real.

Langleben, D. D., Schroeder, L., Maldjian, J. A., Gur, R. C., McDonald, S., Ragland, J. D., . . . Childress, A. R. (2002). Brain Activity during Simulated Deception: An Event-Related Functional Magnetic Resonance Study. NeuroImage, 15, 727-732. doi:10.1006/ nimg.2001.1003

Leonard, A. M. (2006). Naturaleza humana y ley natural. En Consejo Pontificio para la Familia, Lexicón. Términos ambiguos y discutidos sobre familia, vida y cuestiones éticas (Segunda ed.: 821-830). Madrid, España: Ediciones Palabra, S.A.

López-Barajas Zayas, E. (2013). Naturaleza, cultura, ideología y amor. En J. A.-M. Mellado, Educación, libertad y cuidado (págs. 219-238). Madrid, España: Dykinson, S. L.

Madrid Vivar, D. (2002). La mentira infantil: diagnóstico e intervención psicopedagógica. Universidad de Málaga, Facultad de Ciencias de la Educación. Departamento de Métodos de Investigación e Innovación Educativa. Málaga - España: Universidad de Málaga. Recuperado el 6 de Mar de 2016, de http://www.biblioteca.uma.es/bbldoc/tesisuma/1627443x.pdf

Marín, J.-A. N., \& Frápolli Sanz, M. J. (1997). Teorías actuales de la verdad. Diálogo filosófico, 148-178. Recuperado el 6 de Mar de 2016, de https://dialnet.unirioja.es/servlet/ articulo?codigo $=104403$

Nuñez, M. A. (1997). El concepto de verdad en sus dimensiones griega y hebrea. Andrews University Seminary Studies. Springs, 35(1), 47-59. Recuperado el 6 de Mar de 2016, de http://digitalcommons.andrews.edu/cgi/viewcontent.cgi?article=2341\&context=auss

Pascal, B., \& Havet, E. (1852). Pensées de Pascal. París, Francia: Dezobry et E. Magdeleine. Recuperado el 6 de Mar de 2016, de https://books.google.fr/books?id=-Sk-AAAAcAAJ 
Piaget, J. (1984). El criterio moral en el niño (13 ed.). (N. Vidal, Trad.) Barcelona, España: Martínez Roca.

Platón. (1988). Diálogos V: Parménides, Teeteto, Sofista, Político. (I. Santa Cruz, Á. Vallejo Campos, \& C. N. Luis, Trads.) Madrid, España: Editorial Gredos.

Rodríguez Feo, J. (2009). Thomas Hobbes. Tratado sobre el Ciudadano. Madrid, España: Universidad Nacional de Educación a Distancia.

Rodríguez, M. L. (1990). Conocimiento y verdad en el pragmatismo de William James. Enrahonar : quaderns de filosofia(16), 89-104. Recuperado el 6 de Mar de 2016, de https://ddd.uab. cat/pub/enrahonar/0211402Xn16/0211402Xn16p89.pdf

Rousseau, J. J. (1868). El contrato social, o sea, Principios del derecho político. Editorial de Manero.

Rousseau, J. J. (1982). Emilio o la educación (Vol. 33). Edaf.

Rovira-Madrid, R. (2009). La "definición nominal de la verdad" y la "filosofía transcendental de los antiguos". Antonio Millán-Puelles ante la interpretación kantiana de dos doctrinas filosóficas de origen aristotélico. Anuario Filosófico. Revista del Departamento de Filosofía de la Universidad de Navarra, 42(96), 649-673. Recuperado el 6 de Mar de 2016, de http:// dadun.unav.edu/bitstream/10171/22462/2/ROVIRA.pdf

Sotillo Méndez, M., \& Rivière Gómez, Á. (2001). Cuando los niños usan las palabras para engañar: la mentira como instrumento al servicio del desarrollo de las habilidades de inferencia mentalista. Infancia y Aprendizaje: Journal for the Study of Education and Development, 24(3), 291-305. doi:10.1174/021037001316949239

Tamayo y Salmorán, R. (1986). El Derecho y la Ciencia del Derecho (Introducción a la Ciencia Jurídica). México D. F., México: Instituto de Investigaciones Juridicas. Universidad Nacional Autónoma de México.

Tarantino-Curseri, S. (2015). El longevo sofisma -Intelectual Político- o -Político Intelectual-. Eikasia(61), 173-188. Recuperado el 6 de Mar de 2016, de http://revistadefilosofia.com/61-10. pdf

Trankell, A. (1972). Reliability of evidence: Methods for analyzing and assessing witness statements. Oxford, England: Beckmans.

Whiten, A., \& Byrne, R. W. (1988). Tactical deception in primates. Behavioral and brain sciences, 11(2), 233 - 244. doi:10.1017/S0140525X00049682

\section{3}

